
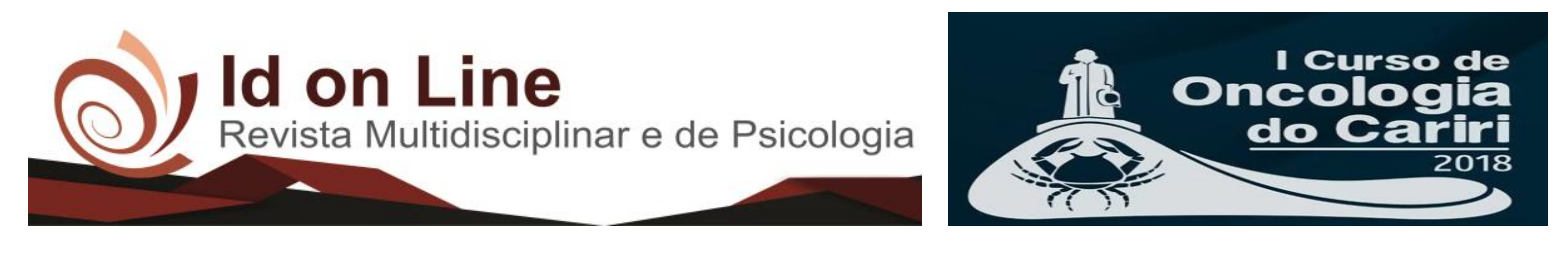

Resumo

\title{
AUTOPERCEPÇÃO E CUIDADOS COM PACIENTE ONCOGERIÁTRICO
}

João Pedro Maciel Capistrano ${ }^{1}$; Ana Paula Barbosa Nóbrega ${ }^{l}$; Marcos Alan Sousa Barbosa ${ }^{1}$; Bruna Raysa Campos Portela²; Rômulo da Nóbrega de Alencar³; Joana Amaral Acioly ${ }^{4}$;

Introdução: A população idosa compõe, hoje, no Brasil, um dos segmentos sociais com maiores valores de crescimento absoluto. Acompanhando esse crescimento, temos um maior número de pacientes oncológicos dentre os indivíduos que fazem parte dessa faixa etária, tendo o impacto global do câncer, de acordo com a Organização Mundial de Saúde, mais que dobrado em apenas 30 anos. $\mathrm{O}$ tratamento oncológico gera mudanças sociais e fisiológicas que poderão afetar tanto a psique quando a saúde física do indivíduo. É necessário avaliar como o paciente reage mediante o tratamento, bem como compreender os impactos que a autopercepção que esse possui tanto de seu estado fisiológico, quanto das consequências que o tratamento pode acarretar e dos impactos que a doença pode gerar em sua vida podem trazer para sua evolução clínica. Objetivo: Entender a necessidade de auxílio médico e multiprofissional no cuidado do paciente geriátrico, bem como compreender a forma com que a percepção que esse possui do seu quadro clínico pode influenciar em sua recuperação ou na evolução do tratamento. Métodos: Realização de uma pesquisa bibliográfica, visando uma revisão sistemática focada nos temas centrais do trabalho relativos as seguintes pesquisas-chave: geriatria, oncologia, autoimagem e tratamentos oncológicos. $\mathrm{O}$ trabalho baseou-se em uma pesquisa qualitativa de caráter exploratório, com orientação analítico-descritiva, sendo feita busca ativa de informações em bases de dados como: MEDLINE, LILACS e biblioteca virtual SciELO. Resultados: Os estudos revisados sugerem a necessidade de entendimento maior da condição de saúde dos pacientes geriátricos, visto que esses possuem condições psicossociais diferenciadas dos pacientes adultos e pediátricos, tendo em vista que há um amplo campo de pesquisa que carece de informações voltadas à temática. Conclusão: É importante entender os efeitos fisiológicos causados pelo uso medicamentoso no tratamento oncológico de idosos, assim como compreender como esse tratamento e o cuidado irão influenciar no entendimento da patologia por parte do doente. Avaliou-se, durante a pesquisa, que os estudos que focam no tratamento oncológico voltado ao público geriátrico estão, em maioria dos casos, relacionados a cuidados paliativos ou relacionados à tanatologia. Sendo necessário, aqui, expandir a compreensão para como o paciente relaciona-se com essa temática e como essa relação influenciará no tratamento.

Palavra-chave: Autoimagem; Cuidados Paliativos; Oncologia; Geriatria.

\footnotetext{
${ }^{1}$ Graduando em Medicina pela Universidade Federal de Campina Grande (UFCG) - Campus Cajazeiras;

${ }^{2}$ Graduanda em Medicina pela Universidade Federal do Cariri (UFCA);

${ }^{3}$ Graduando em Medicina pela Universidade Estadual do Ceará (UECE);

${ }^{4}$ Graduanda em Medicina pelo Centro Universitário Christus (Unichristus);

Autor Correspondente: pedromcapistrano@yahoo.com.br.
}

26 Id on Line Rev. Mult. Psic. V.12, N. 40. 2018 - ISSN 1981-1179 EDIÇÃO ESPECIAL: I CURSO DE ONCOLOGIA DO CARIRI / II JORNADA DE PESQUISA QUANTI-QUALITATIVA EM ONCOLOGIA. JUAZEIRO DO NORTE, 05 A 10 DE MARÇO DE 2018. Edição eletrônica em http://idonline.emnuvens.com.br/id 